\title{
PERANCANGAN, ANALISA DAN SIMULASI RANGKA SEPEDA LISTRIK UNTUK MASYARAKAT PERKOTAAN
}

\author{
Al Ichlas Imran, Samhuddin, Salimin, La Hasanuddin \\ Staf Pengajar Teknik Mesin, Universitas Halu Oleo \\ E-mail: ichlas.imran@uho.ac.id
}

\begin{abstract}
ABSTRAK
Penelitian ini bertujuan untuk merancang dan menganalisa kekuatan frame sepeda listrik dan melakukan simulasi untuk membandingkannya dengan perhitungan manual. Pemilihan material dalam perancangan ini adalah aluminium alloy (Al 6061) dan geometri sepeda ditentulan berdasarkan tabel hubungan jarak antara three-pivot Sepeda. Frame digambar menggunakan autodesk inventor professional 2014, dimana Bagian-bagian Frame disambung dengan metode las. Frame disimulasi menggunakan ansys 16.0, dimana beban pengendara yang diberikan adalah $80 \mathrm{~kg}$. Nilai tegangan maksimum dari perhitungan manual dibandingkan berdasarkan hasil simulasi. Hasil penelitian menunjukkan bahwa nilai tegangan maksimum yang dihasilkan melalui perhitungan manual sebesar 27,398 MPa dan hasil simulasi ansys sebesar 26,658 $\mathrm{MPa}$, dimana keduanya masih dibawah nilai kekuatan material frame yang diizinkan sebesar $46 \mathrm{MPa}$. Hal ini menggambarkan bahwa perancangan sepeda listrik untuk pengguna dengan beban $80 \mathrm{~kg}$ masih dikatakan aman.
\end{abstract}

Kata Kunci: tegangan maksimum, tegangan izin, kekuatan frame, simulasi, aluminium alloy

\section{PENDAHULUAN}

Sepeda listrik merupakan jenis transportasi yang saat ini telah banyak digunakan oleh masyarakat perkotaan. Kendaraan roda dua ini memanfaatkan sistem penggerak manual hasil gerak mekanis kaki yang menggerakan pedal dan sistem penggerak listrik. Perpaduan kedua sumber penggerak tersebut bertujuan untuk meningkatkan kecepatan sepeda dan mengurangi penggunaan tenaga pengendara sepeda.

Selain sebagai sarana transportasi pilihan yang baik untuk daerah perkotaan, sepeda juga memberikan nilai rekreatif dan menunjang pergerakan fisik yang sehat (Mc Cullagh, 1977), dalam perkembangannya untuk mengurangi beban otot yang diterima pengendara serta menambah jarak tempuh sepeda. Oleh karena itu penggunaan sepeda listrik saat ini dimasyarakat telah mengalami peningkatan.

Perancangan sepeda listrik sangat dipengaruhi oleh pemilihan jenis material, desain struktur geometrik dari rangka (frame), beban pengendara, komponen penggerak listrik, biomekanik, kekuatan rangka sepeda dan posisi tubuh pengendara sepeda. Faktor-faktor tersebut akan mempengaruhi kenyaman dan keamanan pengedara serta umur pakai yang dimiliki oleh sepeda (Zhongzia dkk., 2011).

Perancangan frame sepeda listrik dapat dilakukan melalui perhitungan manual atau menggunakan alat bantu simulasi. (Setyono dkk., 2016) melakukan penelitian tentang perancangan dan analisis kekuatan frame sepeda hybrid "trisona" menggunakan software autodesk inventor. Frame berukuran panjang $1200 \mathrm{~mm}$, lebar $180 \mathrm{~mm}$ dan tinggi $618 \mathrm{~mm}$ serta pemberian beban bervariasi dari $0-95 \mathrm{~kg}$. Hasil simulasi menunjukkan, bahwa nilai faktor keamanan terbesar dihasilkan pada pembebanan $0 \mathrm{~kg}(8,93)$ dan terkecil pada pembebanan $95 \mathrm{~kg}(1,99)$, sedangkan pembebanan $95 \mathrm{~kg}$, konstruksi sepeda dinyatakan tidak aman pada lokasi sambungan down tube dan head tube. 
DINAMIKA Jurnal Ilmiah Teknik Mesin

Penelitian lain tentang sepeda listrik juga telah dilakukan oleh Didik (2012). Penelitian ini bertujuan untuk merancang sepeda listrik yang mempunyai desain rangka dari penggabungan dua jenis rangka sepeda yaitu rangka sepeda jalanan dan sepeda gunung. Bahan yang digunakan untuk pembuatan rangka adalah besi St. 37 yang menggunakan metode sambungan jenis las dengan elektroda tipe E 6013. Hasil perhitungan kekuatan rangka diperoleh tegangan tarik maksimum sebesar $18,01 \mathrm{~N} / \mathrm{mm}^{2}$ untuk bahan besi pipa elips dan tegangan tarik maksimum untuk besi pipa profil segi panjang sebesar $53,57 \mathrm{~N} / \mathrm{mm}^{2}$.
Oleh karena itu, peneliti melakukan perancangan, analisa dan simulai rangka sepeda listrik untuk masyarakat perkotaan.

\section{METODE PENELITIAN}

Untuk merancang frame sepeda, pada umumnya memenuhi teori ergonomi, postur tubuh yang paling nyaman bagi pengendara. Oleh karena itu penentuan geometri sepeda menggunkan tabel 1 hubungan jarak antara three-pivot Sepeda (Sadel, Handle dan Pedal) mempengaruhi desain rangka (Zhongzia dkk., 2011).

Tabel 1. Jarak Sadel ke Handle (AC) dan Pedal (AB) ideal untuk tinggi 1500-1800 mm

\begin{tabular}{|c|c|c|c|c|c|c|c|c|}
\hline \multirow{2}{*}{$\begin{array}{c}\text { Tinggi (dalam } \\
\mathrm{mm} \text { ) }\end{array}$} & \multicolumn{2}{|c|}{ Posisi Sadel (A) } & \multicolumn{2}{|c|}{ Posisi Poros Pedal (B) } & \multicolumn{2}{|c|}{ Posisi Handle (C) } & \multirow{2}{*}{ Jarak $A$ ke $C(\mathrm{~mm})$} & \multirow{2}{*}{ Jarak A ke B $(\mathrm{mm})$} \\
\hline & $\mathrm{xA}$ & $\mathrm{yA}$ & $\mathrm{xB}$ & $y B$ & $\mathrm{xC}$ & $\mathrm{yC}$ & & \\
\hline 1500 & -200.624 & 415 & 0 & 0 & 328.025 & 519.262 & 538.8323764 & 460.9500942 \\
\hline 1520 & -197.124 & 429.84 & 0 & 0 & 339.837 & 534.8264 & 547.1278006 & 472.8849112 \\
\hline 1540 & -194.12 & 444.48 & 0 & 0 & 351.073 & 550.1996 & 555.3485762 & 485.0206643 \\
\hline 1560 & -191.613 & 458.92 & 0 & 0 & 361.733 & 565.3816 & 563.4945335 & 497.3159809 \\
\hline 1580 & -189.603 & 473.16 & 0 & 0 & 371.817 & 580.3724 & 571.5655165 & 509.734989 \\
\hline 1600 & -188.09 & 487.2 & 0 & 0 & 381.325 & 595.172 & 579.5613816 & 522.2467694 \\
\hline 1620 & -187.074 & 501.04 & 0 & 0 & 390.257 & 609.7804 & 587.4819966 & 534.8248437 \\
\hline 1640 & -186.554 & 514.68 & 0 & 0 & 398.613 & 624.1976 & 595.3272399 & 547.4467073 \\
\hline 1660 & -186.531 & 528.12 & 0 & 0 & 406.393 & 638.4236 & 603.0969998 & 560.0934056 \\
\hline 1680 & -187.005 & 541.36 & 0 & 0 & 413.597 & 652.4584 & 610.7911731 & 572.7491549 \\
\hline 1700 & -187.976 & 554.4 & 0 & 0 & 420.225 & 666.302 & 618.4096652 & 585.4010049 \\
\hline 1720 & -189.444 & 567.24 & 0 & 0 & 426.277 & 679.9544 & 625.9523889 & 598.0385399 \\
\hline 1740 & -191.408 & 579.88 & 0 & 0 & 431.753 & 693.4156 & 633.4192643 & 610.6536145 \\
\hline 1760 & -193.869 & 592.32 & 0 & 0 & 436.653 & 706.6856 & 640.8102177 & 623.2401215 \\
\hline 1780 & -196.827 & 604.56 & 0 & 0 & 440.977 & 719.7644 & 648.1251818 & 635.7937875 \\
\hline 1800 & -200.282 & 616.6 & 0 & 0 & 444.725 & 732.652 & 655.3640948 & 648.3119924 \\
\hline
\end{tabular}


DINAMIKA Jurnal Ilmiah Teknik Mesin

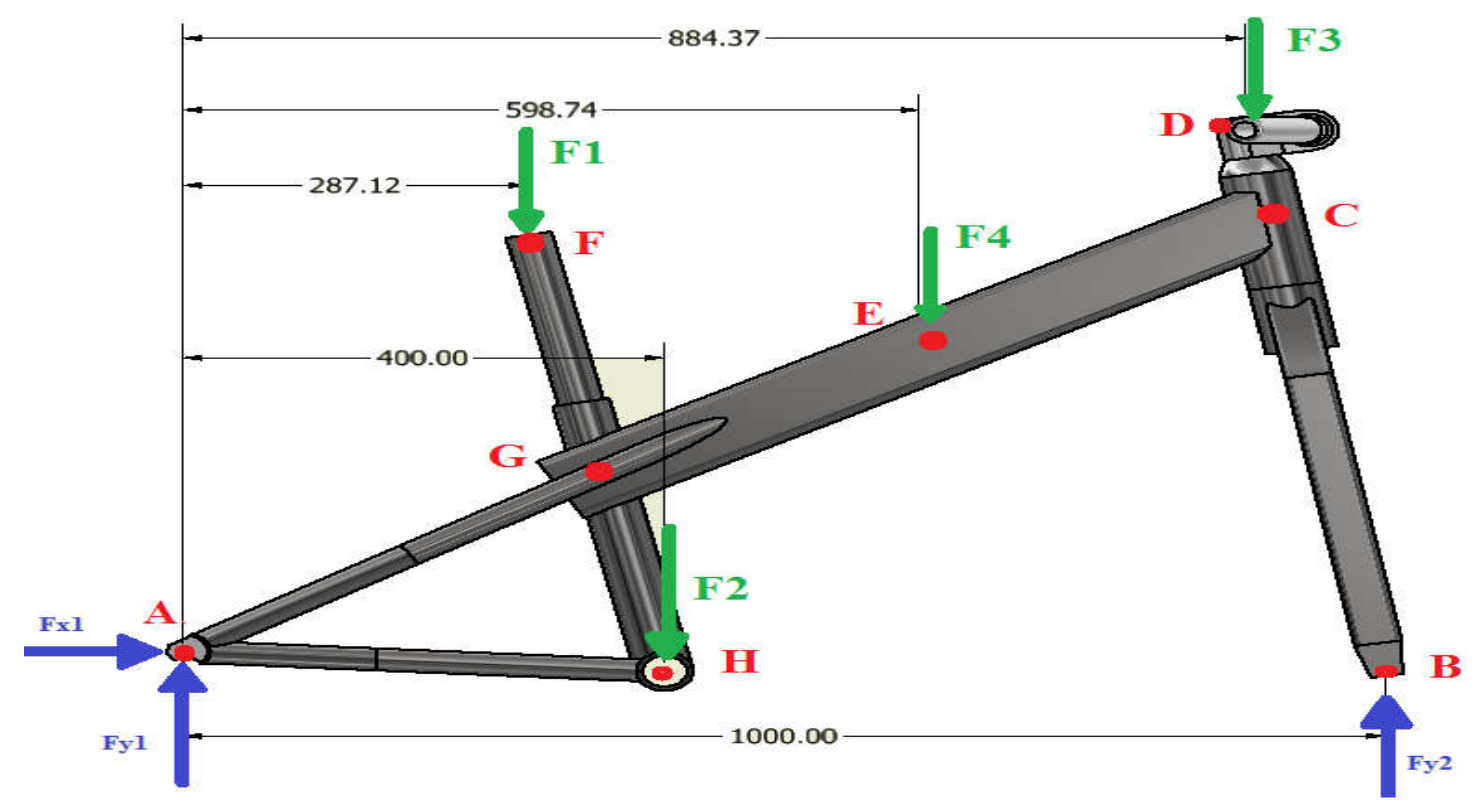

Gambar 1. Titik beban yang diberikan pada rancangan frame sepeda listrik

Prosedur Perancangan

a. Berdasarkan Tabel 3.1, maka geometri yang cocok dengan sampel laki-laki dewasa dengan tinggi badan $164 \mathrm{~cm}$ yaitu jarak sadel ke handle sebesar $595.3272399 \mathrm{~mm}$ dan jarak sadel ke pedak sebesar $547.4467073 \mathrm{~mm}$.

b. Material yang digunakan adalah aluminium alloy (Al 6061) dengan density $2710 \mathrm{Kg} / \mathrm{m}^{3}$.

c. Frame digambar menggunakan softwere autodesk inventor 2017 frame, dimana komponen Baterai dan controller di sisipkan dalam top tube dan menggunakan roda dengan ukuran 27,5 in $\times 2,10$ in atau 6985,5 $\mathrm{mm} \times 53,34 \mathrm{~mm}$.

Analisa Kekuatan Material dan Simulasi

a. Kekuatan material frame dihitung berdasarkan teori pembebanan statis.

b. Beban pengendara dianggap $80 \mathrm{~kg}$, dimana beban akan mempengaruhi nilai gaya $\mathrm{F} 1$ (seatpost), F2 (pedal), F3 (handle) dan F4 (toptube).

c. Gaya untuk posisi F1, F2, F3 dan F4 dianalisa kemudian diperoleh hasil perhitungan beban pada batang $\mathrm{BC}, \mathrm{CD}, \mathrm{EG}, \mathrm{FG}, \mathrm{GH}$, GA dan HA. d. Nilai gaya terbesar yang didapatkan kemudian dibagi dengan luas penampang terkecil pada batang untuk mendapatkan tegangan maksimum $\left(S_{\max }\right)$.

$$
\begin{aligned}
& A_{\text {min }}=\pi\left(\frac{D o}{2}\right)^{2}-\pi\left(\frac{D i}{2}\right)^{2} \\
& \left(S_{\max }\right)=\frac{F}{A_{\min }}
\end{aligned}
$$

e. Setelah itu ditentukan tegangan izin material, dimana nilai faktor keamanan $(\mathrm{N})$ untuk benda bergerak adalah 6 .

$($ Ssyp $)=\frac{S y p}{N}$

Dimana menggunakan nilai yield strength (Syp) material Al 6061

f. Simulasi frame menggunakan Ansys Workbrench 18.2. 
DINAMIKA Jurnal Ilmiah Teknik Mesin

\section{HASIL DAN PEMBAHASAN}

Setelah dilakukan perancangan sepeda listrik (Gambar 1), maka dilakukan analisa reaksi yang terjadi di titik A, B, C, D, E, F, G dan H. Adapun gaya-gaya yang bekerja selama proses pembebanan ditunjukkan pada Tabel 2.

Tabel 2. Gaya-gaya yang bekerja pada sepeda listrik saat pembebanan $80 \mathrm{~kg}$

\begin{tabular}{|c|c|c|c|}
\hline Batang & Gaya $(\mathrm{N})$ & Jenis & Keterangan \\
\hline BC & 341,248 & Tekan & Frok Depan \\
\hline CD & 341,248 & Tekan & Headset \\
\hline EG & 101,833 & Tekan & Top Tube \\
\hline FG & 475,587 & Tekan & Seat Post \\
\hline GH & 149,35 & Tekan & Seat Post Tube \\
\hline GA & 316,481 & Tekan & Seat Stay \\
\hline HA & 3277,77 & Tekan & Chain Stay \\
\hline
\end{tabular}

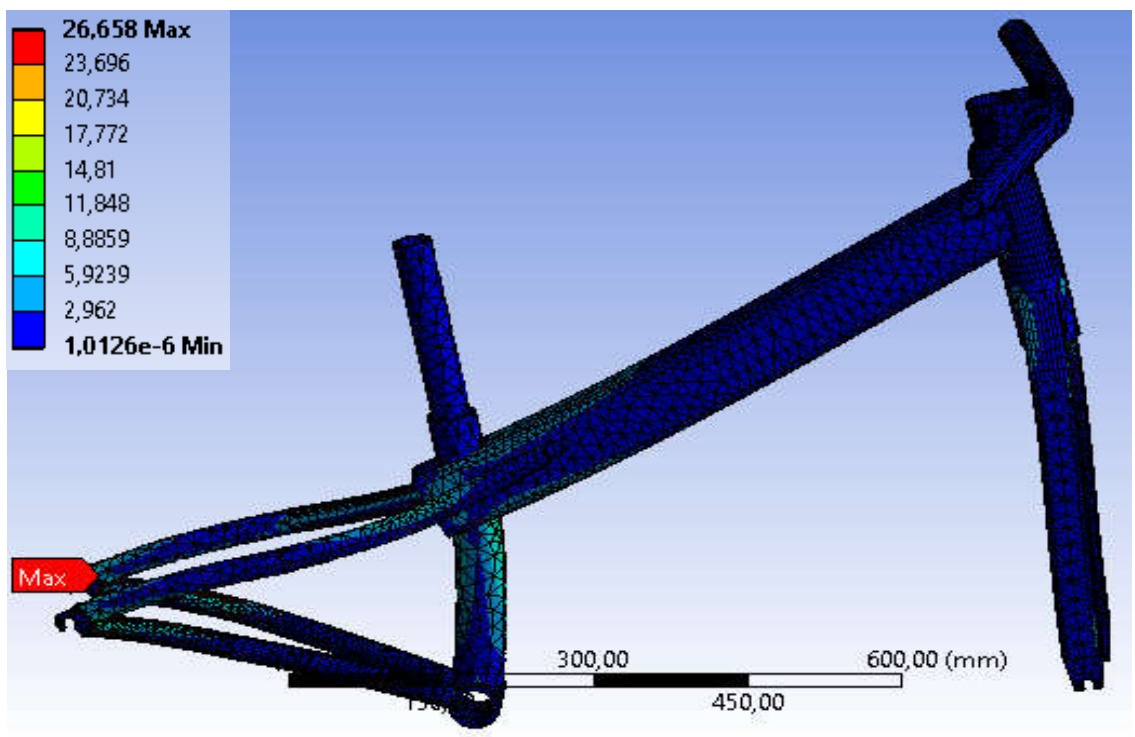

Gambar 2. Hasil simulasi tegangan maksimum 
DINAMIKA Jurnal IImiah Teknik Mesin

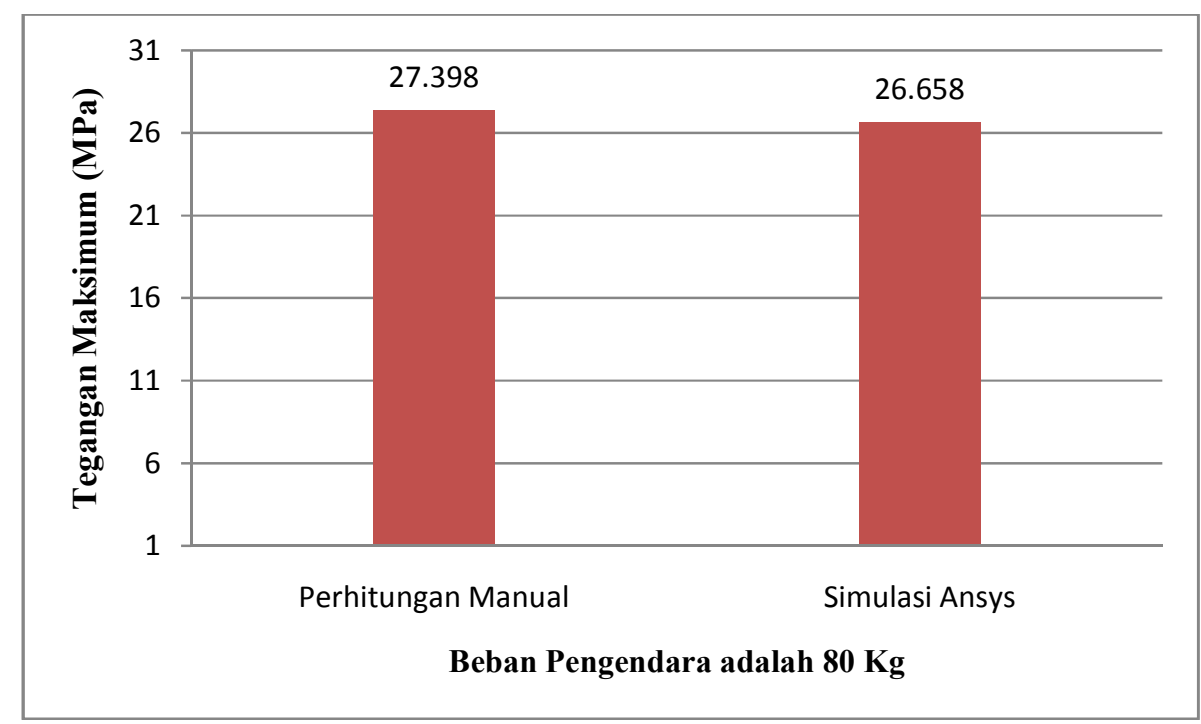

Gambar 3. Perbandingan nilai tegangan maksimum yang dihasilkan oleh perhitungan manual dan simulasi Ansys untuk beban pengendara $80 \mathrm{~kg}$

Gaya yang terbesar terjadi pada batang HA sebesar $3277,77 \mathrm{~N}$ untuk posisi chain stay. Nilai ini kemudian dibagi dengan luas penampang terkecil $\left(A_{\min }=119,634 \mathrm{~mm}^{2}\right)$ pada batang sepeda listrik untuk mengetahui tegangan maksimum yang terjadi pada sepeda 1sitrik. Hal tersebut dilakukan karena batang yang memiliki luas penampang terkecil akan menjadi pusat kosentrasi tegangan atau lebih besar dibandingkan batang yang lain jika sepeda listrik menerima beban pengendara. Gambar 2 juga menggambarkan hasil simulasi sepeda listrik menggunakan ansys, dimana pada batang chain stay telah terjadi tegangan maksimum saat diberikan beban $80 \mathrm{~kg}$.

Berdasarkan gambar 3, dapat diketahui bahwa nilai tegangan maskimum yang dialami oleh sepeda lsitrik berdasarkan perhitungan manual sebesar 27,398 MPa sedangkan melalui simulasi ansys menghasilkan tegangan maksimum sebesar 26,658 MPa, dimana nilai hasil simulasi mendekati nilai hasil perhitungan manual.
Ketika tegangan luluh dari material aluminium alloy $(276 \mathrm{MPa})$ yang digunakan dalam perancangan sepeda listrik ini dibagi dengan faktor keamanan $(\mathrm{N}=6)$ dari benda bergerak, maka tegangan ijin material dari sepeda listrik adalah $46 \mathrm{MPa}$. Tegangan ijin material sangat dibutuhkan sebagai faktor penentu beban pengendara dalam perancangan sepeda listrik.

Dalam perancangan, sepeda lsitrik dikatakan aman jika tegangan maksimum yang dialami saat proses pembebanan tidak melebihi dari tegangan ijin material yang digunakan oleh sepeda. Oleh karena itu, perancangan sepeda listrik ini dengan beban pengendara yang diberikan sebesar $80 \mathrm{~kg}$, masih dalam batas aman dimana nilai 27,398 MPa lebih kecil dari $46 \mathrm{MPa}$. Maka, gambar detail dari perancangan sepeda listrik ini dapat dilihat pada Gambar 4. 


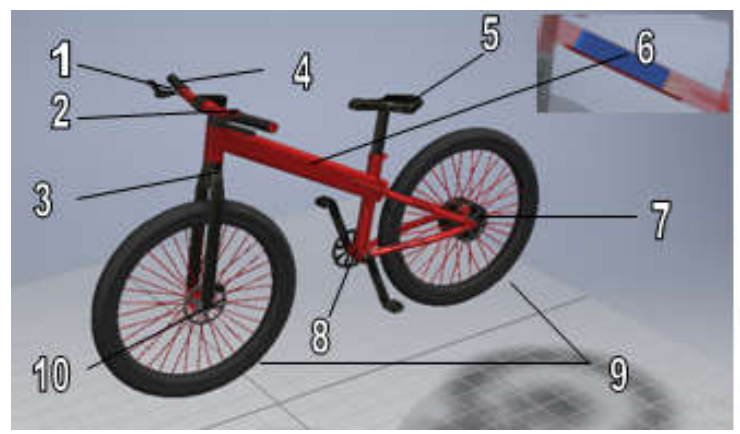

Gambar 4. Sepeda listrik untuk daerah perkotaan

Tabel 3. Nama komponen sepeda listrik dan fungsinya

\begin{tabular}{|c|l|l|}
\hline No & \multicolumn{1}{|c|}{ Nama Komponen } & \multicolumn{1}{c|}{ Fungsi } \\
\hline 1 & Pedal rem & Mengurangi laju atau kecepatan sepeda listrik \\
\hline 2 & Handlebar & Mengendalikan arah sepeda listrik \\
\hline 3 & Fork depan & Tumpuan roda depan \\
\hline 4 & Handelgas & Tengatur laju sepeda listrik \\
\hline 5 & Sadel & Tempat duduk pengendara \\
\hline 6 & Box komponen kelistrikan dan contoller \\
\hline 7 & Motor penggerak/dinamo & $\begin{array}{l}\text { komponen yang berfungsi menghasilkan gerakan putaran } \\
\text { tenaga untuk mendorong sepeda listrik }\end{array}$ \\
\hline 8 & Pedal & Sebagai tumpuan untuk mengayuh sepeda listrik \\
\hline 9 & Roda 27,5 “ & $\begin{array}{l}\text { Penopang sepeda listrik dan penyalur daya dorong dari } \\
\text { kayuhan pedal dan motor penggerak / dinamo }\end{array}$ \\
\hline 10 & Disk Brake & Sistem pengereman Sepeda listrik \\
\hline
\end{tabular}

Frame sepeda listrik dibuat harus memenuhi teori ergonomi, dimana memberikan postur tubuh yang paling nyaman bagi pengendara sepeda serta menunjang untuk perancangan beban pengendara sebesar $80 \mathrm{~kg}$. Komponen - komponen penunjang yang lainnya seperti pedal rem, handlebar, handelgas, motor listrik, seat dan disk brake menggunakan komponen yang sudah ada di pasaran

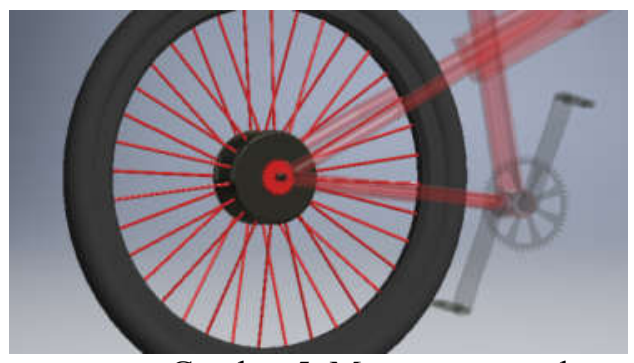

Gambar 5. Motor penggerak
Sistem pengerak pada sepeda listrik ini adalah sproket dan rantai yang digerakan oleh pedal seperti sepeda pada umumnya serta menggunakan motor penggerak/dinamo tipe BLDC yang disimpan pada roda belakang (Gambar 5).

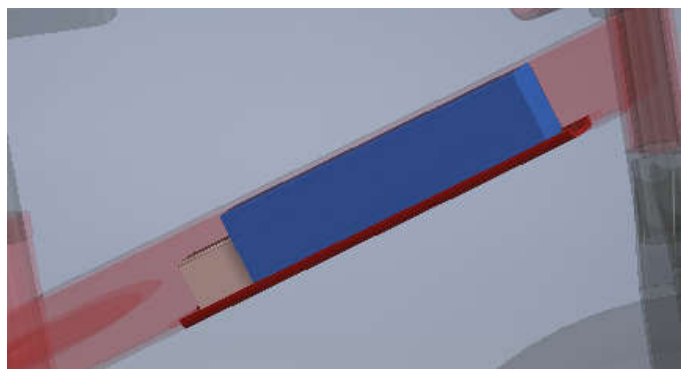

Gambar 6. Komponen kelistrikan

Untuk komponen kelistrikan (Gambar 6) seperti baterai dan controller pada sepeda listrik ini disimpan pada top tube frame sepeda listrik. Box 
komponen kelistrikan mempunyai dimensi sebesar $400 \mathrm{~mm} \times 70 \mathrm{~mm}$ x $50 \mathrm{~mm}$.

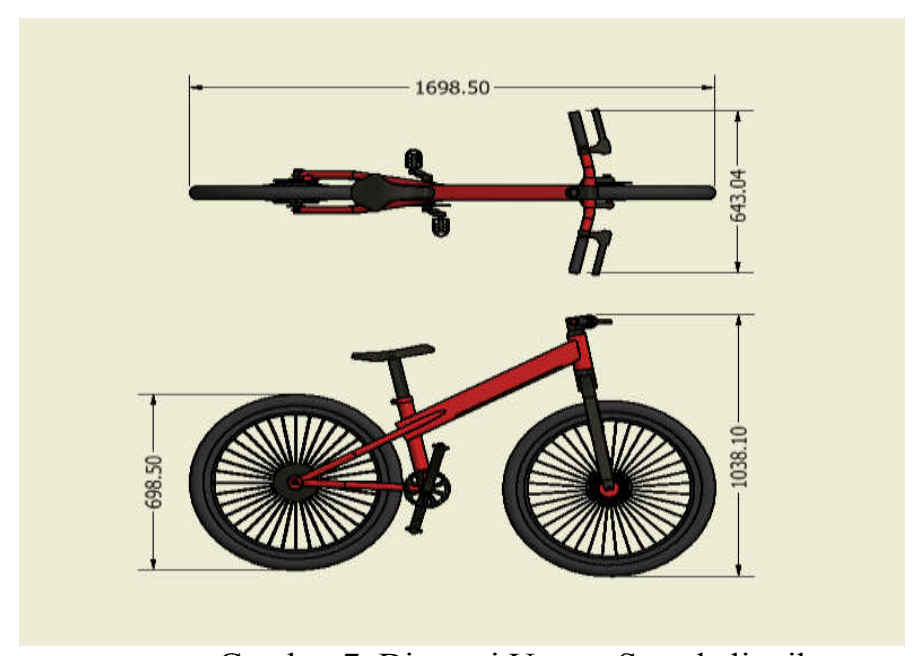

Gambar 7. Dimensi Umum Sepeda listrik

Setelah dilakukan penggabungan semua komponen-komponen penunjang seperti Pedal Rem, Handlebar, Handelgas, Motor listrik, sadel dan disk brake, maka didapatkan dimensi umum sepeda listrik seperti gambar 4.9 dengan panjang total sepeda listrik sepanjang $1698,5 \mathrm{~mm}$, lebar total sebesar $643,04 \mathrm{~mm}$ dan tinggi total sepeda sebesar $1038.10 \mathrm{~mm}$.

\section{KESIMPULAN}

Frame sepeda listrik dirancang berdasarkan table hubungan jarak antara three-pivot Sepeda (Sadel,Handle dan Pedal) ukuran tubuh dewasa dengan menggunakan material aluminium alloy (Al 6061). Komponen listrik diletakakan pada bagian dalam top tube yang menghasilkan kenyamanan bagi pengendara. Frame dirancang dengan beban pengendara $80 \mathrm{~kg}$, dimana tegangan maksimum yang dialami sebesar 27,398 Mpa. Hal ini masih lebih kecil dari tegangan ijin material $\mathrm{Al}$ 6061 sebesar $46 \mathrm{MPa}$, sehingga masih dalam kondisi aman.

\section{DAFTAR PUSTAKA}

1997, ASM Handbook, Properties and Selection, Volume 2, The Materials Information Company. Callister, Jr., W.D. And Rethwisch, D.G, 2010, Materials Science and Engineering And Introductio,. Eighth Edition, Wiley, USA.

Huda, M. dan Tristyono, B., 2015, Desain Sepeda Listrik Untuk Anak Sekolah SMP Dan SMA Yang Menunjang Aktifitas Gaya Hidup Remaja Perkotaan Dan Dapat Diproduksi UKM Lokal, Jurnal Sains Dan Seni ITS, Vol. 4 No.2.

Mc Cullagh, 1977, Pedal Power, Rodale Press, Inc. USA.

Pinem, M.D., 2013, Analisis Sistem Mekanik ANSYS, Wahana Ilmu Kita, Bandung.

Setyono, B., Mrihrenaningtyas dan Hamid, A., 2016, Perancangan Dan Analisis Kekuatan Frame Sepeda Hibrid "Trisona" Menggunakan Software Autodesk Inventor, Jurnal IPTEK, Vol. 20 No. 2.

Yuda, Y.F., 2012, Autodesk Inventor Profesional 2011, Penerbit Andi, Yogyakarta.

Zhongxia, X., Ruifen, X., Yan, B. and Xiaofan, W., 2011, Optimal Design of Biecycle Parameters Considering Biomechanics, Chinese Journal of Mechanical Engineering, Vol. 24 No.1. 